Article

\title{
Association of Polyphenols from Oranges and Apples with Specific Intestinal Microorganisms in Systemic Lupus Erythematosus Patients
}

\author{
Adriana Cuervo ${ }^{1}$, Arancha Hevia ${ }^{2}$, Patricia López ${ }^{1}$, Ana Suárez ${ }^{1}$, Borja Sánchez ${ }^{2, \dagger}$, \\ Abelardo Margolles ${ }^{2}$ and Sonia González ${ }^{1, *}$
}

1 Department of Functional Biology, University of Oviedo, C/Julián Clavería s/n Oviedo, 33006 Asturias, Spain; E-Mails: cuervoadriana.uo@uniovi.es (A.C.); lopezpatricia@uniovi.es (P.L.); anasua@uniovi.es (A.S.)

2 Department of Microbiology and Biochemistry of Dairy Products, Instituto de Productos Lácteos de Asturias-Consejo Superior de Investigaciones Científicas (IPLA-CSIC), Paseo Río Linares s/n Villaviciosa, 33300 Asturias, Spain; E-Mails: ahevia@ipla.csic.es (A.H.); borja.sanchez@uvigo.es (B.S.); amargolles@ipla.csic.es (A.M.)

† Current address: Nutrition and Bromatology Group, Department of Analytical and Food Chemistry; Food Science and Technology Faculty, University of Vigo-Ourense Campus, E-32004 Ourense, Spain.

* Author to whom correspondence should be addressed; E-Mail: soniagsolares@uniovi.es; Tel.: +34-985104209; Fax: +34-985103534.

Received: 18 December 2014 / Accepted: 11 February 2015 / Published: 16 February 2015

Abstract: Our group has recently shown the existence of a gut microbial dysbiosis in systemic lupus erythematosus (SLE), supporting previous evidence involving intestinal bacteria in the initiation and amplification of autoimmune diseases. While several studies have addressed the use of dietary fibres to modify intestinal microbiota, information about other correlated components, such as polyphenols, is scarce. The aim of this work was to identify dietary components able to influence this altered microbiota in 20 SLE women and 20 age-matched controls. Food intake was recorded by means of a food frequency questionnaire. The intake of fibres was calculated from Marlett tables, and Phenol-Explorer was used for polyphenol consumption. Results showed positive associations between flavone intake and Blautia, flavanones and Lactobacillus, and dihydrochalcones and Bifidobacterium in the SLE group. Regarding the controls, dihydroflavonols were directly associated with Faecalibacterium, whereas flavonol intake was inversely associated with Bifidobacterium. From the food sources of these polyphenols related to microbiota, orange 
intake was directly associated with Lactobacillus and apple with Bifidobacterium in SLE, whilst red wine was the best contributor to Faecalibacterium variation. The association between common foods and particular microbial genera, reported to be decreased in SLE, could be of great importance for these patients.

Keywords: lupus; polyphenols; microbiota; orange; apple, red wine

\section{Introduction}

Gut microbiota has been related to the modulation of the immune system and to anti-oxidant defence [1-3]. We have recently published the existence of a gut microbial dysbiosis in patients with systemic lupus erythematosus (SLE). The decrease in the ratio of Firmicutes to Bacteroidetes in SLE subjects [4] supports previous evidence involving intestinal bacteria in the initiation and amplification of inflammatory processes and autoimmune diseases [5-7]. In this regard, common clinical features associated with SLE, such as intestinal vasculitis, could have an influence on the observed dysbiosis. In relation to this, high Bacteroidetes levels have also been found in patients with inflammatory bowel disease [8]. In this context, it has been reported that patients with metabolic syndrome fed with a low fat/high carbohydrate diet suffered an increase in Bacteroides spp. and Bifidobacterium spp. [9]. Other previous studies have positively associated levels of Firmicutes with a low-fat/high-fibre diet [10] and the increase in Firmicutes/Bacteroidetes ratio with whole grain supplementation [11]. Also, it has been found that the microbiota of people with a long-term diet rich in animal protein and saturated fat presents more Bacteroides [12]. Apart from this, other bioactive compounds from diet, such as polyphenols, are able to modulate the intestinal microbiome [13], and have shown promising results in models of autoimmune diseases [14]. To date, there are few studies which have focused on the interactions between polyphenol intake and microbiota: evidence from animal and human studies has shown that supplementation with polyphenol-rich food, such as red wine [15], tea [13], cocoa [16] or blueberries [17,18], modulates some intestinal bacterial populations, but the results were not conclusive. While Queipo-Ortuño et al. have recently published changes in Proteobacteria, Fusobacteria, Firmicutes and Bacteroidetes concentrations in humans after dietary intervention with alcoholic beverages (red wine and gin) and de-alcoholized red wine [15], animal studies have found a lower proportion of Clostridium and Lactobacillus in polyphenoltreated rats with respect to the control [19]. Moreover, the effects of cocoa flavanols remain controversial: an increase in Lactobacillus and Bacteroides has been described in humans [20], but evidence in animal studies showed a decrease of Bacteroides, Clostridium and Staphylococcus [16].

Thus, as this imbalance is susceptible to being modified by shifting dietary patterns, the overall aim of this paper was the identification of dietary components associated with this altered microbiota. Knowledge of the interactions between diet and microbiota in SLE subjects may be useful in the future to establish some basis for the rational design of functional foods and dietary intervention strategies meant to improve the clinical manifestations of these chronic patients. 


\section{Subjects and Methods}

The study sample comprised 20 SLE patients selected from the updated Asturian Register of Lupus [21]. All of them fulfilled at least four of the American College of Rheumatology criteria for SLE [22], were women of Caucasian origin, aged between 35-70 years and had no active disease at the time of sampling (Systemic Lupus Erythematosus Disease Activity Index (SLEDAI) score $\leq 8$ ). Patients were also asked precise questions regarding treatment received during the previous 6 months. Only those individuals who had not used antibiotics, glucocorticoids, immunosuppressive drugs, monoclonal antibodies, or other immunotherapies were recruited for the study. Eighteen patients were receiving antimalarial treatment, and all of them were regular consumers of nonsteroidal anti-inflammatory drugs. Twenty age-matched healthy women from the same population were recruited as controls.

Ethics approval for this study (reference code AGL2010-14952; grant title "Towards a better understanding of gut microbiota functionality in some immune disorders") was obtained from the Bioethics Committee of CSIC (Consejo Superior de Investigaciones Científicas) and from the Regional Ethics Committee for Clinical Research (Servicio de Salud del Principado de Asturias, $n^{\circ} 13 / 2010$ ) in compliance with the Declaration of Helsinki. All determinations were performed with fully informed written consent from all participants involved in the study.

\subsection{Nutritional Assessment}

Dietary intake was assessed by means of an annual semi-quantitative food-frequency questionnaire (FFQ) of 160 items, previously validated for polyphenol intake in other samples [23]. The FFQ was organized by groups of food and open-ended, allowing foods consumed by the subject and not registered in the questionnaire to be recorded. During a personal interview, subjects were asked item-by-item whether they usually ate each food (daily, weekly or monthly), and, if so, how much they usually ate. To facilitate the recording of the quantities of food consumed, 3 different serving sizes of each cooked food were presented in pictures to the participants, so that they could choose from up to 7 serving sizes (from "less than the small one" to "more than the large one"). For some of the foods consumed, amounts were recorded in household units, by volume, or by measuring with a ruler. Special attention was paid to cooking practices, number and amount of ingredients used in each recipe, as well as questions concerning menu preparation (e.g., type of oil used, type of milk) and other relevant information for the study, such as the consumption of skin in fruit. Furthermore, variability in the consumption of some foods, especially fruits and vegetables, according to the season was taken into account. The consumption of foods was converted into energy and saturated fatty acid intake using the nutrient Food Composition Tables developed by the Centro de Enseñanza Superior de Nutrición Humana y Dietética (CESNID) [24]. Dietary fibre was determined from Marlett Food Composition Tables [25] and animal protein from the USDA Database [26]. The content of flavonoids in the foods consumed in the sample, with the exception of spices and condiments, was calculated using the Phenol-Explorer Database. This database contains detailed information of the polyphenol content in more than 400 foods, mainly determined by highperformance liquid chromatography (HPLC), gas chromatography (GC), and capillary electrophoresis (CE), and is compiled from more than 1300 publications, being at the moment one of the main tools used in human studies [27]. 


\subsection{Anthropometric Measures}

Body mass index (BMI) was calculated using Quetelet formula. Weight was measured on a scale with an accuracy of $\pm 100 \mathrm{~g}$ (Seca, Hamburg, Germany). Height was registered using a stadiometer with an accuracy of $\pm 1 \mathrm{~mm}$ (Año-Sayol, Barcelona, Spain). Subjects stood barefoot, in an upright position and with the head positioned in the Frankfort horizontal plane.

\subsection{Microbiological Analyses}

Faecal DNA extraction, 16S rRNA amplification sequencing of 16S rRNA gene-based amplicons and the sequence-based microbiota analysis were reported elsewhere [4]. The raw sequences reported in this article are deposited in the NCBI Short Read Archive (SRA) (study accession number: SRP028162).

\subsection{Statistical Analysis}

Statistical analysis was performed using IBM-SPSS version 19.0 (SPSS-Inc., Chicago). Goodness of fit to normal distribution was analysed with the Kolmogorov-Smirnov test. Since the relative abundance of Lactobacillus did not fulfill this criterion, the variable was logarithmically transformed to perform the analysis. For descriptive purposes, mean values were presented on untransformed variables. Multivariate analysis, including age and energy intake, were conducted to examine the difference in the mean intake of animal protein, saturated fatty acids, dietary fibre and flavonoids between SLE patients and controls, while the Student $t$-test was used to evaluate the difference in consumption of the main food sources of flavonoids. In order to investigate the association between the intake of animal protein, saturated fatty acids, dietary fibre and flavonoids and faecal relative abundance of the studied microorganisms, multiple linear regression analysis was carried out. Age and energy intake were also included as covariates in the models. The main food sources of the dietary components previously related to microbiota were selected and placed in a multiple stepwise regression analysis to explore their independent effect. The statistical parameters employed were $\beta$ (standardized regression coefficient) and $R^{2}$ (coefficient of multiple determinations).The conventional probability value for significance (0.05) was used in the interpretation of results. Considering the standard deviation of the microbial relative abundance and the standard deviation of the regression errors, we could reject the null hypothesis with an estimated probability around 0.8 and a type I error probability of 0.05 for the three models (calculated using the software PS: Power and Sample Size Calculation version 3.0.43 (Vanderlbilt University, Nashville, TN, USA)).

\section{Results}

General characteristics and daily intake of dietary components previously associated with microbiota are compared between SLE patients and control subjects in Table 1. Both groups were similar for all the studied variables. 
Table 1. Characteristics of the evaluated variables in systemic lupus erythematosus (SLE) and controls.

\begin{tabular}{|c|c|c|c|}
\hline & $\operatorname{SLE}(N=20)$ & Control $(N=20)$ & Reference \\
\hline Age (year) & $49.25 \pm 10.71$ & $46.95 \pm 8.60$ & {$[4]$} \\
\hline $\mathrm{BMI}\left(\mathrm{kg} \cdot \mathrm{m}^{-2}\right)$ & $26.11 \pm 5.31$ & $25.17 \pm 4.16$ & {$[4]$} \\
\hline Energy $\left(\mathrm{kcal} \cdot \mathrm{day}^{-1}\right)^{\mathrm{a}}$ & $2189.65 \pm 722.42$ & $1858.53 \pm 332.85$ & {$[4]$} \\
\hline Animal protein $\left(g \cdot \text { day }^{-1}\right)^{a, b}$ & $104.70 \pm 27.60$ & $100.85 \pm 20.86$ & This work \\
\hline Saturated fatty acids $\left(g \cdot \text { day }^{-1}\right)^{\mathrm{a}, \mathrm{b}}$ & $25.19 \pm 14.09$ & $24.66 \pm 6.04$ & {$[4]$} \\
\hline Dietary fiber $\left(g \cdot \text { day }^{-1}\right)^{a, b}$ & $18.06 \pm 10.04$ & $20.32 \pm 8.52$ & {$[4]$} \\
\hline Total flavonoids (mg $\cdot$ day $^{-1}$ ) a,b & $400.13 \pm 259.94$ & $436.34 \pm 189.70$ & This work \\
\hline Anthocyanins $\left(\mathrm{mg} \cdot \mathrm{day}^{-1}\right)^{\mathrm{a}, \mathrm{b}}$ & $20.81 \pm 30.30$ & $29.73 \pm 30.65$ & \\
\hline Dihydrochalcones (mg $\cdot$ day $^{-1}$ ) a,b & $2.70 \pm 4.42$ & $3.26 \pm 3.58$ & \\
\hline Dihydroflavonols (mg day $^{-1}$ ) ${ }^{\mathrm{a}, \mathrm{b}}$ & $0.34 \pm 0.80$ & $1.96 \pm 2.82 *$ & \\
\hline Flavanols $\left(\mathrm{mg} \cdot \mathrm{day}^{-1}\right)^{\mathrm{a}, \mathrm{b}}$ & $298.54 \pm 222.16$ & $283.47 \pm 160.21$ & \\
\hline Flavanones $\left(\mathrm{mg} \cdot \text { day }^{-1}\right)^{\mathrm{a}, \mathrm{b}}$ & $38.22 \pm 29.44$ & $45.31 \pm 32.81$ & \\
\hline Flavones (mg·day $\left.{ }^{-1}\right)^{\mathrm{a}, \mathrm{b}}$ & $2.48 \pm 2.39$ & $3.96 \pm 3.92$ & \\
\hline Flavonols $\left(\mathrm{mg} \cdot \mathrm{day}^{-1}\right.$ ) & $38.00 \pm 30.26$ & $52.05 \pm 25.55$ & \\
\hline Isoflavones $\left(\mathrm{mg} \cdot \text { day }^{-1}\right)^{\mathrm{a}, \mathrm{b}}$ & $5.52 \pm 16.81$ & $15.92 \pm 66.13$ & \\
\hline
\end{tabular}

Multivariate analysis adjusted by ${ }^{\mathrm{a}}$ age and ${ }^{\mathrm{b}}$ energy intake; Results are presented as estimated marginal mean $\pm \mathrm{SD} ; * p \leq 0.05$.

In order to explore the association between dietary components and faecal microbiota with independence of age and energy intake, linear regression analysis was conducted. Animal protein, saturated fatty acids and dietary fibre were not associated with microbial genera in any of the studied groups (Table 2).

Table 2. Linear regression analyses for daily intake of animal protein, saturated fatty acids (SFA) and dietary fiber on fecal microbial in patients with systemic lupus erythematosus (SLE) and controls.

\begin{tabular}{|c|c|c|c|c|c|c|c|}
\hline & \multirow[t]{2}{*}{ Group } & \multicolumn{2}{|c|}{$\begin{array}{c}\text { Animal protein } \\
\left(\mathrm{g} \cdot \mathrm{day}^{-1}\right)\end{array}$} & \multicolumn{2}{|c|}{$\operatorname{SFA}\left(g \cdot \mathrm{day}^{-1}\right)$} & \multicolumn{2}{|c|}{ Dietary fiber $\left(\mathrm{g} \cdot \mathrm{day}^{-1}\right)$} \\
\hline & & $R^{2}$ & $\boldsymbol{\beta}$ & $R^{2}$ & $\beta$ & $R^{2}$ & $\beta$ \\
\hline \multirow{2}{*}{ Blautia (\%) } & $\mathrm{L}$ & 0.129 & 0.206 & 0.273 & -0.874 & 0.109 & 0.129 \\
\hline & $\mathrm{C}$ & 0.028 & -0.117 & 0.016 & 0.031 & 0.046 & -0.205 \\
\hline \multirow{2}{*}{ Clostridium (\%) } & $\mathrm{L}$ & 0.271 & 0.431 & 0.170 & 0.363 & 0.140 & -0.116 \\
\hline & $\mathrm{C}$ & 0.116 & 0.343 & 0.007 & 0.026 & 0.007 & -0.022 \\
\hline \multirow[t]{2}{*}{ Lactobacillus (\%) } & $\mathrm{L}$ & 0.041 & -0.237 & 0.024 & -0.312 & 0.031 & 0.225 \\
\hline & $\mathrm{C}$ & 0.203 & -0.347 & 0.091 & -0.030 & 0.174 & 0.336 \\
\hline \multirow[t]{2}{*}{ Lactococcus (\%) } & $\mathrm{L}$ & 0.345 & 0.447 & 0.213 & -0.193 & 0.218 & 0.150 \\
\hline & $\mathrm{C}$ & 0.065 & -0.210 & 0.029 & -0.086 & 0.029 & -0.085 \\
\hline
\end{tabular}


Table 2. Cont.

\begin{tabular}{|c|c|c|c|c|c|c|c|}
\hline & \multirow[t]{2}{*}{ Group } & \multicolumn{2}{|c|}{$\begin{array}{l}\text { Animal protein } \\
\left(\mathrm{g} \cdot \mathrm{day}^{-1}\right)\end{array}$} & \multicolumn{2}{|c|}{ SFA $\left(g \cdot\right.$ day $\left.^{-1}\right)$} & \multicolumn{2}{|c|}{ Dietary fiber $\left(\mathrm{g} \cdot \mathrm{day}^{-1}\right)$} \\
\hline & & $R^{2}$ & $\boldsymbol{\beta}$ & $R^{2}$ & $\boldsymbol{\beta}$ & $R^{2}$ & $\boldsymbol{\beta}$ \\
\hline \multirow[t]{2}{*}{ Faecalibacterium (\%) } & $\mathrm{L}$ & 0.063 & -0.111 & 0148 & 0.641 & 0.086 & -0.232 \\
\hline & $\mathrm{C}$ & 0.143 & 0.272 & 0.075 & 0.028 & 0.074 & 0.000 \\
\hline \multirow[t]{2}{*}{ Bacteroides (\%) } & $\mathrm{L}$ & 0.005 & -0.026 & 0.017 & 0.232 & 0.118 & 0.439 \\
\hline & $\mathrm{C}$ & 0.125 & 0.110 & 0.291 & 0.483 & 0.115 & -0.045 \\
\hline \multirow[t]{2}{*}{ Bifidobacterium (\%) } & $\mathrm{L}$ & 0.121 & -0.126 & 0.147 & 0.402 & 0.299 & 0.567 \\
\hline & $\mathrm{C}$ & 0.323 & -0.154 & 0.302 & -0.046 & 0.371 & -0.309 \\
\hline
\end{tabular}

L = SLE $(N=20)$; C = Control $(N=20)$; SFA = Saturated Fatty Acids; Results derived from multiple linear regression analysis including age and energy intake as covariates; $R^{2}$ : coefficient of multiple determinations; $\beta$ : standardized regression coefficient.

The associations found between flavonoid classes and microbiota are illustrated in Figure 1a,b. Results showed positive associations between flavone intake and Blautia, flavanones and Lactobacillus and dihydrochalcones and Bifidobacterium in SLE group. Regarding the control group, dihydroflavonols were directly associated with Faecalibacterium, whereas flavanol and flavonol intake were inversely associated with Bifidobacterium. Given the high correlation with flavonoids from foods, an additional stepwise regression analysis was conducted to explore the relative importance of flavanol and flavonol intake on Bifidobacterium. Flavonol intake was found to be an independent contributor to this microbial group (data not shown). To explore these associations, the main food sources of these flavonoids were calculated (Figure 2a,b). In SLE subjects, oranges and their products were the top contributors to both flavones and flavanones, while dihydrochalcones came exclusively from apple intake. In controls, dihydroflavonols were provided from red wine, and other foods such as tea, spinach and walnuts contributed to explain $45 \%$ of flavonol intake. 

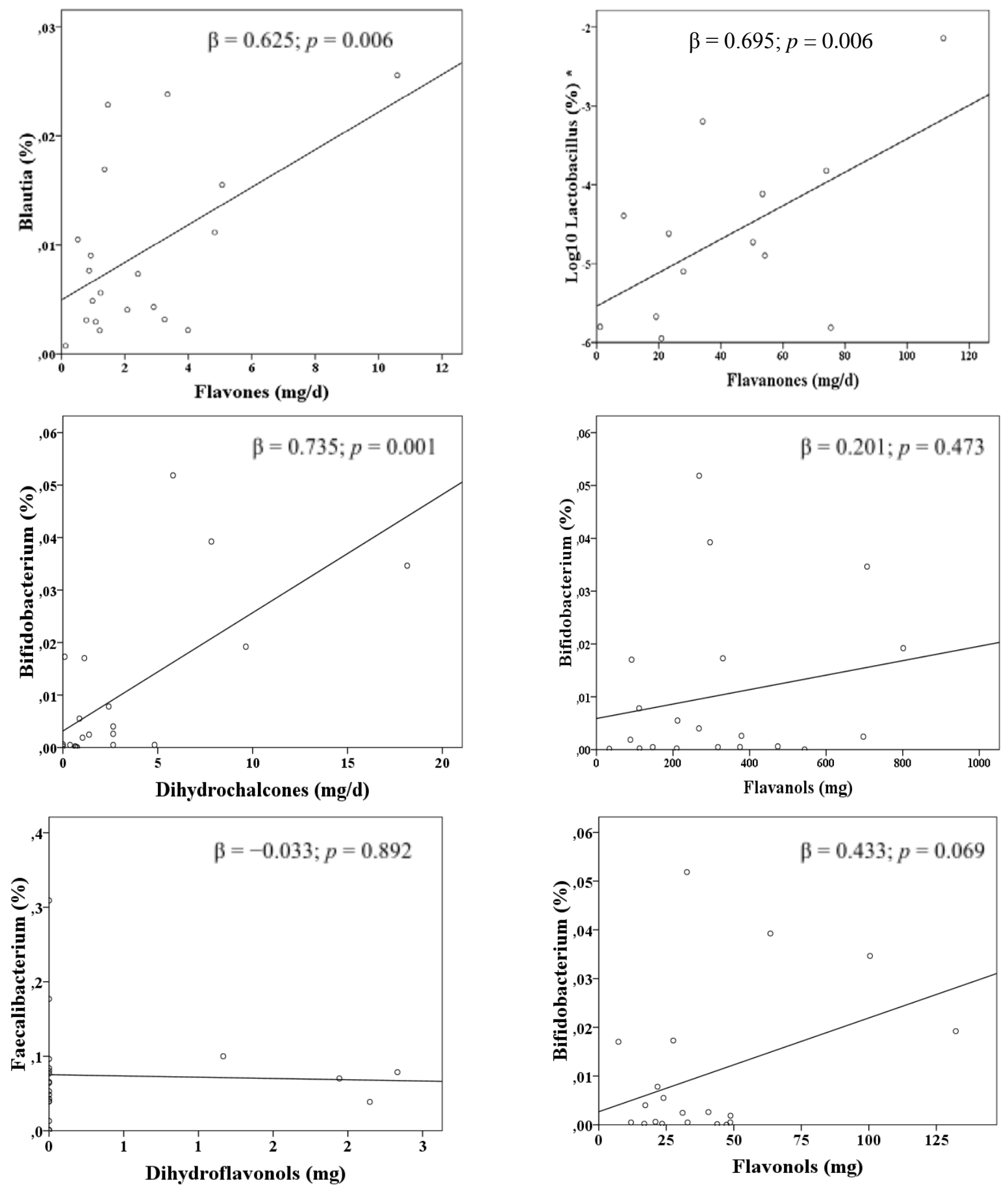

(a)

Figure 1. Cont. 

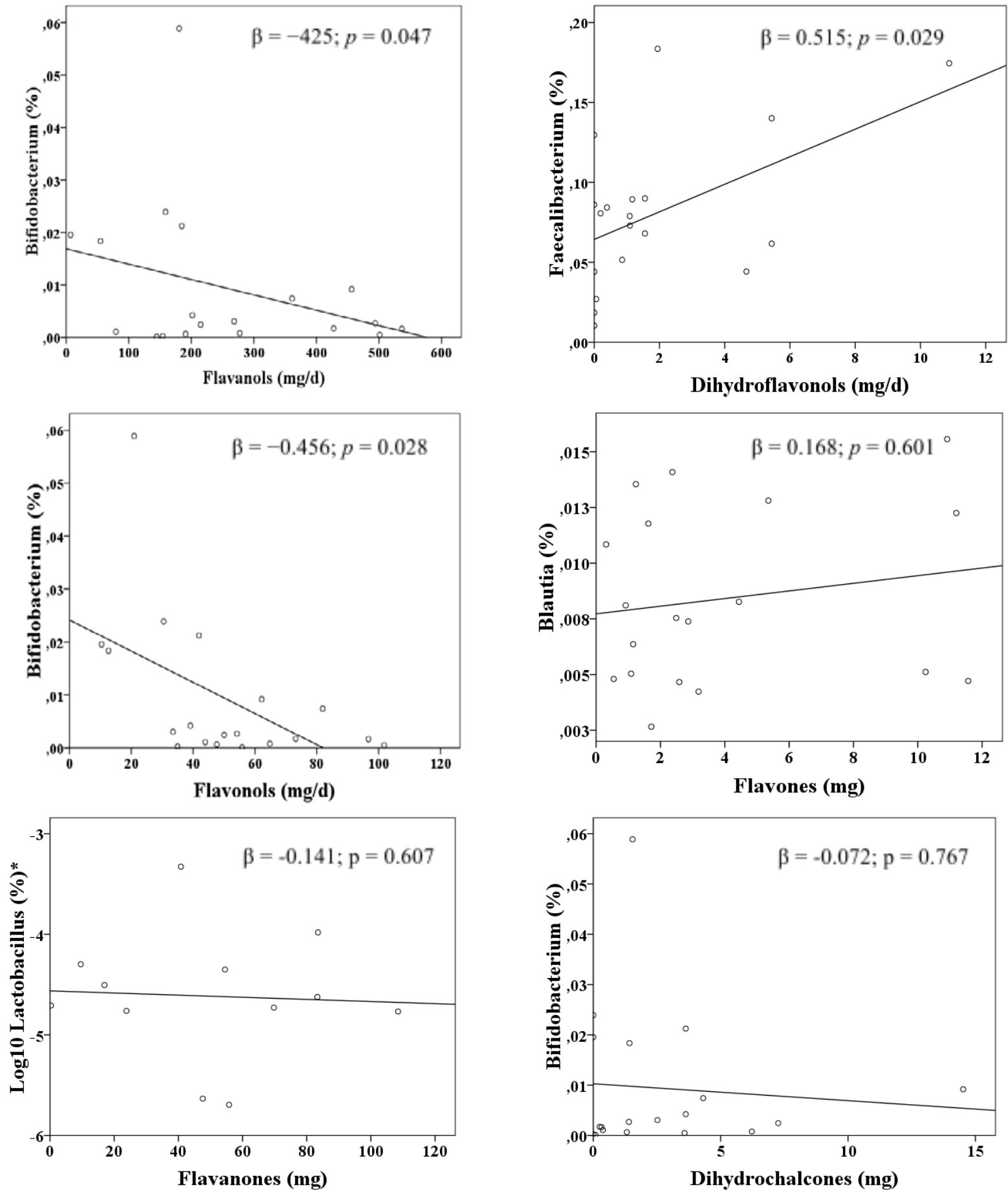

(b)

Figure 1. (a) Linear estimation trends between the intake of some classes of flavonoids and the proportion of selected microbial genera, in systemic lupus erythematosus patients. Results derived from multiple linear regression analyses including age and energy intake as covariates. (b) Linear estimation trends between the intake of some classes of flavonoids and the proportion of selected microbial genera, in controls. Results derived from multiple linear regression analyses including age and energy intake as covariates. * Logarithmically transformed variable. 


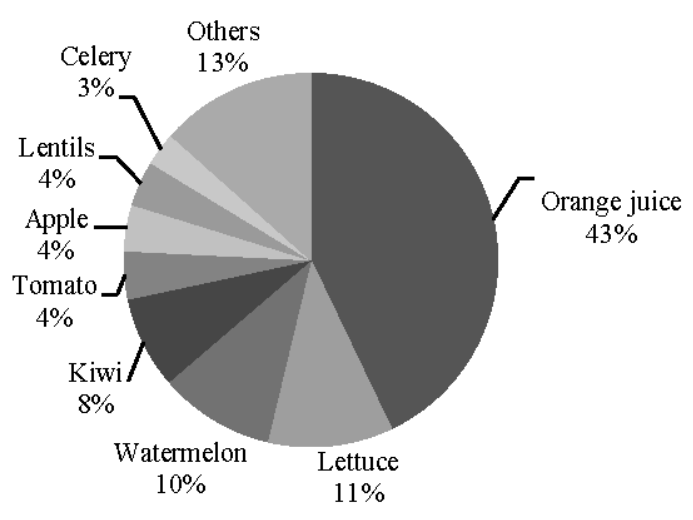

Flavones



Dihydrochalcones

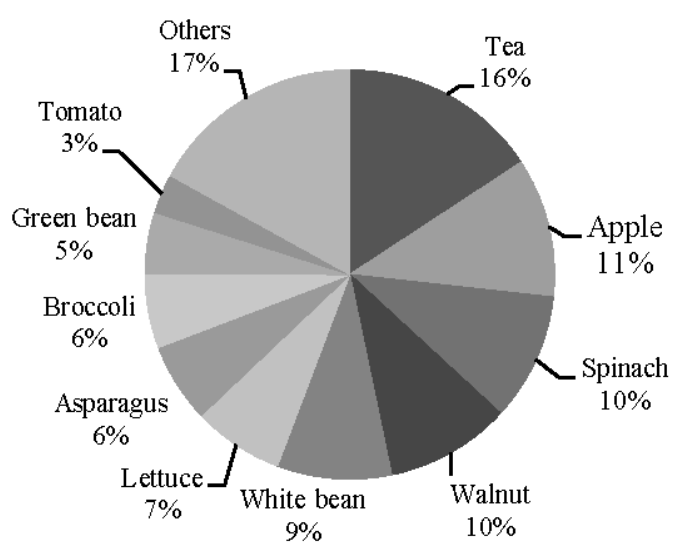

Flavonols

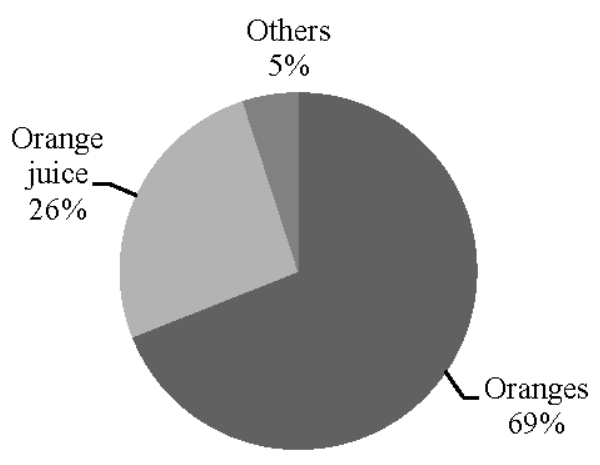

Flavanones

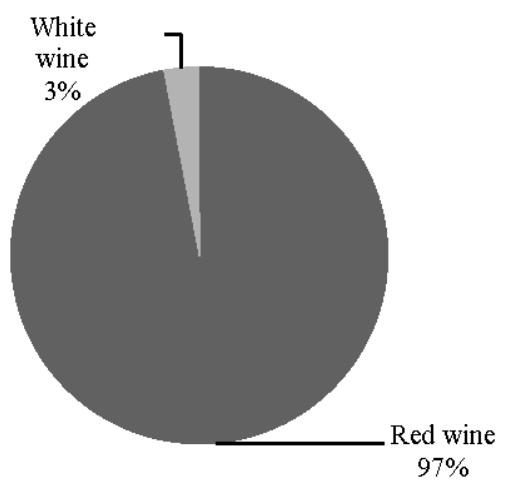

Dihydroflavonols

(a)

Figure 2. Cont. 




Flavones

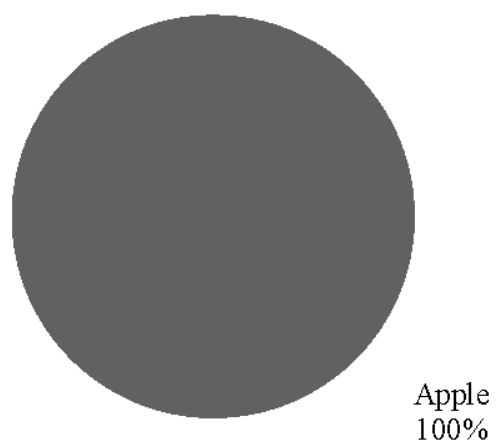

Dihydrochalcones

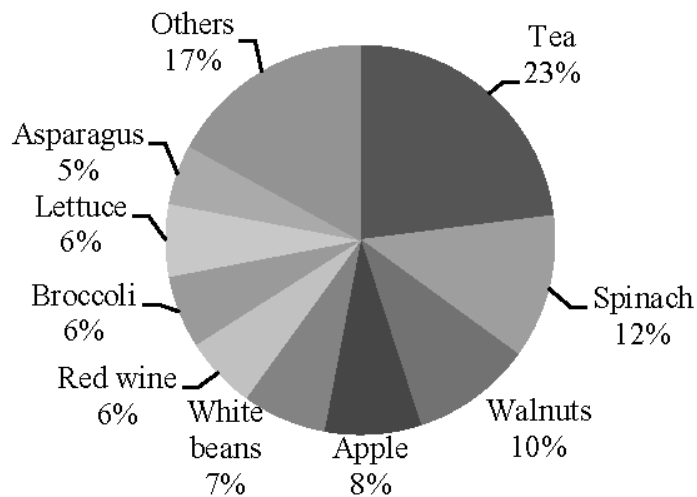

Flavonols

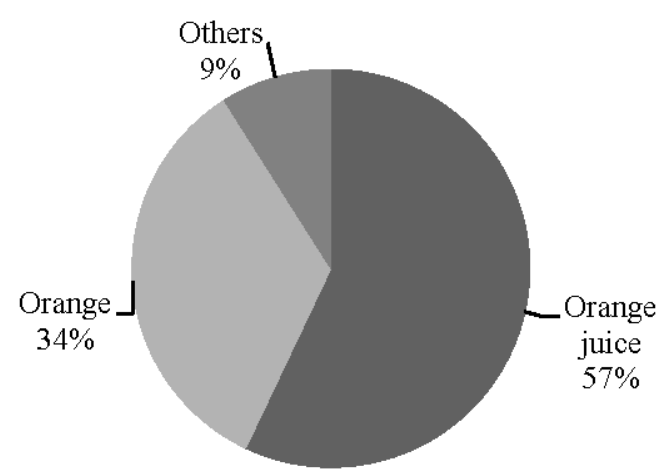

Flavanones

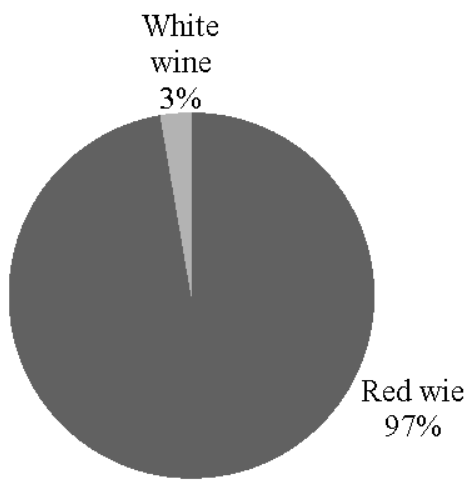

Dihydroflavonols

(b)

Figure 2 (a) Principal food sources of the flavonoid classes previously associated with fecal microbiota, in systemic lupus erythematosus patients. (b) Principal food sources of the flavonoid classes previously associated with fecal microbiota, in controls.

We did not find differences in the intake of any food sources, with the exception of red wine, which had greater consumption in controls (Table 3). 
Table 3. Mean intake of the selected food sources of flavonoids in systemic lupus erythematosus (SLE) patients and controls.

\begin{tabular}{|c|c|c|}
\hline & $\operatorname{SLE}(N=20)$ & Control $(N=20)$ \\
\hline Orange $\left(\mathrm{g} \cdot \mathrm{day}^{-1}\right)$ & $58.43 \pm 72.24$ & $34.51 \pm 42.75$ \\
\hline Orange juice (g·day ${ }^{-1}$ ) & $17.94 \pm 33.69$ & $51.51 \pm 73.53$ \\
\hline Lettuce $\left(\mathrm{g} \cdot\right.$ day $^{-1}$ ) & $50.63 \pm 30.19$ & $50.22 \pm 42.66$ \\
\hline Watermelon $\left(\mathrm{g} \cdot \mathrm{day}^{-1}\right.$ ) & $10.79 \pm 19.11$ & $7.01 \pm 13.83$ \\
\hline Kiwi $\left(g \cdot\right.$ day $\left.^{-1}\right)$ & $21.19 \pm 29.50$ & $25.11 \pm 62.61$ \\
\hline Tomato $\left(\mathrm{g} \cdot \mathrm{day}^{-1}\right)$ & $84.06 \pm 51.58$ & $72.77 \pm 48.13$ \\
\hline Apple $\left(\mathrm{g} \cdot \mathrm{day}^{-1}\right)$ & $77.81 \pm 81.87$ & $58.72 \pm 63.59$ \\
\hline Lentils (g/day) & $8.02 \pm 5.12$ & $9.31 \pm 7.69$ \\
\hline Celery $\left(\mathrm{g} \cdot\right.$ day $\left.^{-1}\right)$ & $0.18 \pm 0.80$ & $0.45 \pm 1.51$ \\
\hline Red wine $\left(\mathrm{mL} \cdot\right.$ day $\left.^{-1}\right)$ & $6.79 \pm 14.37$ & $34.20 \pm 52.34 *$ \\
\hline White wine $\left(\mathrm{mL} \cdot\right.$ day $\left.^{-1}\right)$ & $1.79 \pm 7.99$ & $8.95 \pm 34.30$ \\
\hline Tea $\left(\mathrm{mL} \cdot\right.$ day $\left.^{-1}\right)$ & $51.52 \pm 156.22$ & $93.82 \pm 172.59$ \\
\hline Spinach $\left(\mathrm{g} \cdot \mathrm{day}^{-1}\right)$ & $3.01 \pm 6.15$ & $4.44 \pm 5.76$ \\
\hline Walnuts $\left(\mathrm{g} \cdot\right.$ day $^{-1}$ ) & $6.014 \pm 11.24$ & $7.75 \pm 10.77$ \\
\hline White beans $\left(\mathrm{g} \cdot \mathrm{day}^{-1}\right)$ & $6.61 \pm 4.20$ & $6.82 \pm 7.13$ \\
\hline Broccoli $\left(\mathrm{g} \cdot \mathrm{day}^{-1}\right.$ ) & $6.16 \pm 10.63$ & $7.64 \pm 9.47$ \\
\hline Asparagus $\left(\mathrm{g} \cdot \mathrm{day}^{-1}\right.$ ) & $9.66 \pm 9.96$ & $8.80 \pm 14.87$ \\
\hline Green beans $\left(\mathrm{g} \cdot \mathrm{day}^{-1}\right)$ & $8.08 \pm 15.56$ & $11.59 \pm 12.36$ \\
\hline
\end{tabular}

Derived from Students' $t$-test; Results are presented as mean $\pm \mathrm{SD}$; * $p \leq 0.05$.

From foods, orange and apple intake explained $38 \%$ and $44 \%$ of relative abundance for Lactobacillus and Bifidobacterium, respectively, in SLE subjects, whereas red wine was positively associated with Faecalibacterium in the control (Table 4).

Table 4. Results from a stepwise multiple regression analysis for prediction of relative abundance of fecal microbiota by the intake of the principal food sources of flavonoids in systemic lupus erythematosus (SLE) and control subjects.

\begin{tabular}{|c|c|c|c|c|}
\hline & Predictors & $\boldsymbol{R}^{2}$ & $\beta$ & $p$ \\
\hline \multicolumn{5}{|l|}{$\operatorname{SLE}(N=20)$} \\
\hline Lactobacillus $^{\text {a }}$ & Orange & 0.383 & 0.619 & 0.004 \\
\hline Bifidobacterium ${ }^{\text {b }}$ & Apple & 0.437 & 0.661 & 0.001 \\
\hline \multicolumn{5}{|l|}{ Controls $(N=20)$} \\
\hline Faecalibacterium $^{\mathrm{c}}$ & Red wine & 0.264 & 0.514 & 0.024 \\
\hline
\end{tabular}




\section{Discussion}

Systemic lupus erythematosus is a multisystemic chronic inflammatory disease that is autoimmune in nature. Although the cause of this pathology is unknown, accumulating evidence suggests that gut microbiota might impact both disease symptoms and progression. To date, there is no clear evidence about the impact of correcting dysbiosis in these patients, but the identification of dietary factors able to modify the microbial balance could be important for future investigations. With this aim, we proceeded to analyse the association among dietary components and microbiota.

Most previous works about the impact of diet on this disease are focused on the immunomodulatory effects of the supplementation, or restriction of some dietary components, including calorie, protein or fat intake [28-30], on the basis that the fact of having a pathological condition could implicate changes in food supply. However, the comparison of the global intake between SLE patients and controls presented in this study reveals that the nutritional intake of both groups is similar and, therefore, there is no dietary constituent significantly raised or lowered in relation to the presence of the pathology.

Despite previous evidence from intervention studies with high-fat diets suggesting that excessive fat intake leads to changes in the proportion of Bacteroides and Clostridium [31], our results do not support a relationship between fat intake and these bacterial groups in humans with well-balanced diets. Also, we did not find differences in faecal microbiota according to the intake of animal protein or fibre intake. It is possible that the amounts of these dietary components in our sample were insufficient to have an impact on faecal microbiota or, as some authors have suggested, that the food combinations of a diet modify the effect of dietary single components [32]. In this regard, it has been reported that the negative effects of high-fat diets were different when fat was administrated with orange juice $v$ s. water or glucose solution [32], probably due to the high levels of antioxidant bioactive compounds, such as flavonoids, present in this beverage, and proposed in recent years as gut microbiota modulators [33].

Likely, the most important finding of this study is the identification of a direct association, in SLE patients, between flavanones, flavones and dihydrochalcones, coming from a regular diet, and faecal levels of Blautia, Lactobacillus and Bifidobacterium, together with the detection of an inverse association between flavonol intake and faecal levels of Bifidobacterium, and positive one for dihydroflavonols and Faecalibacterium in control subjects. The positive association between orange flavanones and Lactobacillus proportions found in this study is not in accordance with previous evidence of the antimicrobial activity of these flavonoids [34]. Nevertheless, we have limited information about the role of individual flavonoids on microbiota to be able to compare our results, taking into consideration that results from in vitro studies cannot be directly extrapolated to what occurs in the physiological context of the intestinal ecosystem, and intervention work often involves very high doses of individual compounds, or high doses of polyphenol rich foods (tea, coffee or cocoa being the most frequent), which are not representative of what occurs in a regular diet.

It is known that the natural presence of flavonoids within foodstuffs and their interaction with other dietary components, such as fibres, may modify the level of polyphenols available to the gut microbiota [35]. In this sense, it is possible that dihydrochalcones from apples, along with dietary fibre, are degraded by Bifidobacterium, promoting its growth. This effect of apple polyphenols, previously reported in animal models and humans [36,37], should be of special interest for SLE patients given the immunomodulatory effect attributed to some strains of this bacterial genus [38], such as B. bifidum LMG13195, a strain that 
promoted the induction of regulatory $\mathrm{T}$ cells (Tregs), expressing chemokine receptors and potentially favouring mucosal homeostasis [1,2]. Dihydrochalcones have also been shown to influence the commensal intestinal microbiota, increasing the levels of some bacteria in the gut, such as Lactobacillus species [39]. As these beneficial groups of microorganisms trigger immunomodulatory processes in the host through the action of metabolites or other secreted compounds, administration of dihydrochalcones might have an impact on host immunity, although this assumption deserves further work [40].

Even though flavones were widely distributed among fruits and vegetables in the sample (oranges, lettuce, watermelon, kiwi, tomato, apple, etc.), none of their sources were identified as independent predictors of Blautia proportion, so we speculate that the observed associations could be attributable to the combination of all flavone-rich foods present in a whole diet, unlike flavanones and dihydrochalcones, which are provided almost exclusively by oranges and apples, respectively. Since Clostridium-dependent induction of Tregs may be required for maintaining immune homeostasis, and considering that Blautia belongs to Clostridium cluster XIVa, which promotes Treg cell accumulation, this result could also be of interest for other autoimmune diseases [41].

It is noteworthy that the associations observed in SLE patients did not appear in the controls, which means that in addition to the differences in the food sources of these compounds, it is possible that the variability in the composition of gut microbiota between groups may involve different diet-microbiota associations [42,43], or that subjects with a well-balanced immune system could be less susceptible to the effect of dietary components than subjects with altered immune responses. The influence of red wine on Faecalibacterium concentrations has not been previously described, but it is in agreement with the reported changes in the phylum Firmicutes after red wine administration [15], supporting the hypothesis about the prebiotic effect of moderate red wine consumption [19]. On the other hand, the inverse association between flavonols and Bifidobacterium is in accordance with data from in vitro studies [44]. It is possible that the lack of association in SLE patients may be due to the low intake of red wine in this group compared to the controls (5.9 \pm 8.9 vs. $35.1 \pm 9.1 \mathrm{~mL} \cdot$ day $^{-1}$ respectively). Since $80 \%$ of the SLE sample did not consume red wine, we had no statistical power to detect any association with this beverage.

\section{Conclusions}

Finally, although epidemiological analyses do not establish causality, our findings support the association between polyphenols from a regular diet and faecal microbiota. The association between common foods, such as oranges and apples, with specific microorganisms reported to be decreased in SLE could be of great importance for these patients. It could also be of great interest for future studies to explore the functional changes occurring in SLE intestines and how they affect the various impacts of dietary flavonoids on microbiota for a healthy population. Even when causality between changes in the Firmicutes/Bacteroidetes ratio and lupus progression requires further validation, these results will generate new hypotheses to test dietary strategies to correct dysbiosis in this pathology, suggesting a new therapeutic approach to treat autoimmunity diseases. 


\section{Acknowledgments}

This study was financed by European Union FEDER funds and the Spanish Plan Nacional de I+D (grant AGL2010-14952). We are most grateful to the Asociación Lúpicos Asturias (ALAS) and all the volunteers participating in the study.

\section{Author Contributions}

A.C. conducted the nutritional data analyses and the manuscript elaboration; A.H., B.S. and A.M. carried out the microbiological analyses; and P.L. and A.S. were responsible for the recruitment of SLE patients. S.G. was responsible for the study design, data collection and manuscript preparation. All authors critically reviewed the manuscript and approved the final version submitted for publication.

\section{Conflicts of Interest}

The authors declare no conflict of interest.

\section{References}

1. Lopez, P.; Gonzalez-Rodriguez, I.; Gueimonde, M.; Margolles, A.; Suarez, A. Immune response to Bifidobacterium bifidum strains support Treg/Th17 plasticity. PLoS One 2011, 6, e24776.

2. Lopez, P.; Gonzalez-Rodriguez, I.; Sanchez, B.; Ruas-Madiedo, P.; Suarez, A.; Margolles A.; Gueimonde, M. Interaction of Bifidobacterium bifidum LMG13195 with HT29 cells influences regulatory-T-cell-associated chemokine receptor expression. Appl. Environ. Microbiol. 2012, 78, 2850-2857, doi:10.1128/AEM.07581-11.

3. Maslowski, K.M.; Mackay, C.R. Diet, gut microbiota and immune responses. Nat. Immunol. 2011, 12, 5-9, doi:10.1038/ni0111-5.

4. Hevia, A.; Milani, C.; López, P.; Cuervo, A.; Arboleya, S.; Duranti, S.; Turroni, F.; González, S.; Suárez, A.; Gueimonde, M.; et al. Intestinal dysbiosis associated with Systemic Lupus Erythematosus. mBio 2014, 5, e01548-e01614.

5. Berer, K.; Mues, M.; Koutrolos, M.; Rasbi, Z.A.; Boziki, M.; Johner, C.; Wekerle, H.; Krishnamoorthy, G. Commensal microbiota and myelin autoantigen cooperate to trigger autoimmune demyelination. Nature 2011, 479, 538-541.

6. Markle, J.G.; Frank, D.N.; Mortin-Toth, S.; Robertson, C.E.; Feazel, L.M.; Rolle-Kampczyk, U.; von Bergen, M.; McCoy, K.D.; Macpherson, A.J.; Danska, J.S. Sex differences in the gut microbiome drive hormone-dependent regulation of autoimmunity. Science 2013, 339, 1084-1088.

7. Proal, A.D.; Albert, P.J.; Marshall, T.G. The human microbiome and autoimmunity. Curr. Opin. Rheumatol. 2013, 25, 234-240.

8. Manichanh, C.; Rigottier-Gois, L.; Bonnaud, E.; Gloux, K.; Pelletier, E.; Frangeul, L.; Nalin, R.; Jarrin, C.; Chardon, P.; Marteau, P.; et al. Reduced diversity of faecal microbiota in Crohn’s disease revealed by a metagenomic approach. Gut 2006, 55, 205-211. 
9. Fava, F.; Gitau, R.; Griffin, B.A.; Gibson, G.R.; Tuohy, K.M.; Lovegrove, J.A. The type and quantity of dietary fat and carbohydrate alter faecal microbiome and short-chain fatty acid excretion in a metabolic syndrome at-risk population. Int. J. Obes. 2013, 37, 216-223.

10. Wu, G.D.; Chen, J.; Hoffmann, C.; Bittinger, K.; Chen, Y.Y.; Keilbaugh, S.A.; Bewtra, M.; Knights, D.; Walters, W.A.; Knight, R.; et al. Linking long-term dietary patterns with gut microbial enterotypes. Science 2011, 334, 105-108.

11. Martinez, I.; Lattimer, J.M.; Hubach, K.L.; Case, J.A; Yang, J.; Weber, C.G.; Louk, J.A.; Rose, D.J.; Kyureghian, G.; Peterson, D.A.; et al. Gut microbiome composition is linked to whole grain1induced immunological improvements. ISME J. 2013, 7, 269-280.

12. Yatsunenko, T.; Rey, F.E.; Manary, M.J.; Trehan, I.; Dominguez-Bello, M.G.; Contreras, M.; Magris, M.; Hidalgo, G.; Baldassano, R.N.; Anokhin, A.P.; et al. Human gut microbiome viewed across age and geography. Nature 2012, 486, 222-227.

13. Lee, H.C.; Jenner, A.M.; Low, C.S.; Lee, Y.K. Effect of tea phenolics and their aromatic fecal bacterial metabolites on intestinal microbiota. Res. Microbiol. 2006, 157, 876-884.

14. Schoenroth, L.J.; Hart, D.A.; Pollard, K.M.; Fritzler, M.J. The effect of the phytoestrogen coumestrol on the NZB/W F1 murine model of systemic lupus. J. Autoimmun. 2004, 23, 323-332.

15. Queipo-Ortuno, M.I.; Boto-Ordonez, M.; Murri, M.; Gomez-Zumaquero, J.M.; Clemente-Postigo, M.; Estruch, R.; Cardona, D.F.; Andres-Lacueva, C.; Tinahones, F.J. Influence of red wine polyphenols and ethanol on the gut microbiota ecology and biochemical biomarkers. Am. J. Clin. Nutr. 2012, 95, 1323-1334.

16. Massot-Cladera, M.; Perez-Berezo, T.; Franch, A.; Castell, M.; Perez-Cano, F.J. Cocoa modulatory effect on rat faecal microbiota and colonic crosstalk. Arch. Biochem. Biophys. 2012, 527,105-112.

17. Guglielmetti, S.; Fracassetti, D.; Taverniti, V.; Del, B.C.; Vendrame, S.; Klimis-Zacas, D.; Arioli, S.; Riso, P.; Porrini, M. Differential modulation of human intestinal bifidobacterium populations after consumption of a wild blueberry (Vaccinium angustifolium) drink. J. Agric. Food Chem. 2013, 61, 8134-8140.

18. Vendrame, S.; Guglielmetti, S.; Riso, P.; Arioli, S.; Klimis-Zacas, D.; Porrini, M. Six-week consumption of a wild blueberry powder drink increases bifidobacteria in the human gut. J. Agric. Food Chem. 2011, 59, 12815-12820.

19. Dolara, P.; Luceri, C.; De, F.C.; Femia, A.P.; Giovannelli, L.; Caderni, G.; Cecchini, C.; Silvi, S.; Orpianesi, C.; Cresci, A. Red wine polyphenols influence carcinogenesis, intestinal microflora, oxidative damage and gene expression profiles of colonic mucosa in F344 rats. Mutat. Res. 2005, 591, 237-246.

20. Tzounis, X.; Rodriguez-Mateos, A.; Vulevic, J.; Gibson, G.R.; Kwik-Uribe, C.; Spencer, J.P. Prebiotic evaluation of cocoa-derived flavanols in healthy humans by using a randomized, controlled, double-blind, crossover intervention study. Am. J. Clin. Nutr. 2011, 93, 62-72.

21. Lopez, P.; Mozo, L.; Gutierrez, C.; Suarez, A. Epidemiology of systemic lupus erythematosus in a northern Spanish population, gender and age influence on immunological features. Lupus 2003, 12, 860-865. 
22. Tan, E.M.; Cohen, A.S.; Fries, J.F.; Masi, A.T.; McShane, D.J.; Rothfield, N.F.; Schaller, J.G.; Talal, N.; Winchester, R.J. The 1982 revised criteria for the classification of systemic lupus erythematosus. Arthritis Rheum. 1982, 25, 1271-1277.

23. Cuervo, A.; Valdes, L.; Salazar, N.; de los Reyes-Gavilan, C.G.; Ruas-Madiedo, P.; Gueimonde, M.; Gonzalez, S. Pilot study of diet and microbiota, interactive associations of fibers and polyphenols with human intestinal bacteria. J. Agric. Food Chem. 2014, 62, 5330-5336.

24. Centro de Enseñanza Superior de Nutrición Humana y Dietética (CESNID). Tablas de Composición de Alimentos por Medidas Caseras de Consumo Habitual en España, 1st ed.; McGraw-Hill Interamericana de España S.L: Barcelona, Spain, 2008; pp. 1-288.

25. Marlett, J.A.; Cheung, T.F. Database and quick methods of assessing typical dietary fiber intakes using data for 228 commonly consumed foods. J. Am. Diet. Assoc. 1997, 10, 1139-1151.

26. United States Department of Agriculture (USDA). Agricultural Research Service. USDA National Nutrient Database for Standard Reference. Available online: http://www.ars.usda.gov/Services/ docs.htm?docid=8964 (accessed on 14 February 2012).

27. Neveu, V.; Perez-Jimenez, J.; Vos, F.; Crespy, V.; du, C.L.; Mennen, L.; Knox, C.; Eisner, R.; Cruz, J.; Wishart, D.; et al. Phenol-Explorer, an online comprehensive database on polyphenol contents in foods. Database 2010, bap024.

28. Auborn, K.J.; Qi, M.; Yan, X.J.; Teichberg, S.; Chen, D.; Madaio, M.P.; Chiorazzi, N. Lifespan is prolonged in autoimmune-prone (NZB/NZW) F1 mice fed a diet supplemented with indole-3-carbinol. J. Nutr. 2003, 133, 3610-3613.

29. Lai, N.S.; Lin, R.H.; Lai, R.S.; Kun, U.C.; Leu, S.C. Prevention of autoantibody formation and prolonged survival in New Zealand Black/New Zealand White F1 mice with an ancient Chinese herb, Ganoderma tsugae. Lupus 2001, 10, 461-465.

30. Sawai, C.; Anderson, K.; Walser-Kuntz, D. Effect of bisphenol A on murine immune function; modulation of interferon-gamma, IgG2a, and disease symptoms in NZB X NZW F1 mice. Environ. Health Perspect. 2003, 111, 1883-1187.

31. De La Serre, C.B.; Ellis, C.L.; Lee, J.; Hartman, A.L.; Rutledge, J.C.; Raybould, H.E. Propensity to high-fat diet-induced obesity in rats is associated with changes in the gut microbiota and gut inflammation. Am. J. Physiol. Gastrointest. Liver Physiol. 2010, 299, 440-448.

32. Ghanim, H.; Sia, C.L.; Upadhyay, M.; Korzeniewski, K.; Viswanathan, P.; Abuaysheh, S.; Mohanty, P.; Dandona, P. Orange juice neutralizes the proinflammatory effect of a high-fat, high-carbohydrate meal and prevents endotoxin increase and Toll-like receptor expression. Am. J. Clin. Nutr. 2010, 91, 940-949.

33. Selma, M.V.; Espin, J.C.; Tomas-Barberan, F.A. Interaction between phenolics and gut microbiota, role in human health. J. Agric. Food Chem. 2009, 57, 6485-64501.

34. Celiz, G.; Audisio, M.C.; Daz, M. Antimicrobial properties of prunin, a citric flavanone glucoside, and its prunin 6"-O-lauroyl ester. J. Appl. Microbiol. 2010, 109, 1450-1457.

35. Schantz, M.; Erk, T.; Richling, E. Metabolism of green tea catechins by the human small intestine. Biotechnol. J. 2010, 5, 1050-1059. 
36. Sembries, S.; Dongowski, G.; Jacobasch, G.; Mehrlander, K.; Will, F.; Dietrich, H. Effects of dietary fibre-rich juice colloids from apple pomace extraction juices on intestinal fermentation products and microbiota in rats. Br. J. Nutr. 2003, 90, 607-715.

37. Sembries, S.; Dongowski, G.; Mehrlander, K.; Will, F.; Dietrich, H. Physiological effects of extraction juices from apple, grape, and red beet pomaces in rats. J. Agric. Food Chem. 2006, 54, 10269-10280.

38. Konieczna, P.; Akdis, C.A.; Quigley, E.M.; Shanahan, F.; O’Mahony, L. Portrait of an immunoregulatory Bifidobacterium. Gut Microbes 2012, 3, 261-266.

39. Daly, K.; Darby, A.C.; Hall, N.; Nau, A.; Bravo, D.; Shirazi-Beechey, S.P. Dietary supplementation with lactose or artificial sweetener enhances swine gut Lactobacillus population abundance. $B r . J$. Nutr. 2014, 111, 30-35.

40. Ruiz, L.; Hevia, A.; Bernardo, D.; Margolles, A.; Sanchez, B. Extracellular molecular effectors mediating probiotic attributes. FEMS Microbiol. Lett. 2014, 359, 1-11.

41. Atarashi, K.; Tanoue, T.; Shima, T.; Imaoka, A.; Kuwahara, T.; Momose, Y.; Cheng, G.; Yamasaki, S.; Saito, T.; Ohba, Y.; et al. Induction of colonic regulatory T cells by indigenous Clostridium species. Science 2011, 331, 337-341.

42. Cerda, B.; Tomas-Barberan, F.A.; Espin, J.C. Metabolism of antioxidant and chemopreventive ellagitannins from strawberries, raspberries, walnuts, and oak-aged wine in humans, identification of biomarkers and individual variability. J. Agric. Food Chem. 2005, 53, 227-235.

43. Gross, G.; Jacobs, D.M.; Peters, S.; Possemiers, S.; van Duynhoven, J.; Vaughan, E.E.; van de Wiele, T. In vitro bioconversion of polyphenols from black tea and red wine/grape juice by human intestinal microbiota displays strong interindividual variability. J. Agric. Food Chem. 2010, 58, 10236-10246.

44. Duda-Chodak, A. The inhibitory effect of polyphenols on human gut microbiota. J. Physiol. Pharmacol. 2012, 63, 497-503.

(C) 2015 by the authors; licensee MDPI, Basel, Switzerland. This article is an open access article distributed under the terms and conditions of the Creative Commons Attribution license (http://creativecommons.org/licenses/by/4.0/). 